\title{
Load Frequency Control (LFC) Menggunakan Metode Noise-Tolerable PID Feedback pada Power Generation Plant Simulator PLTU PT. Pembangkitan Jawa dan Bali (PJB) Unit Pembangkitan (UP) Paiton
}

\author{
Rahmadhi Prihandono, Mochammad Rameli \\ Jurusan Teknik Elektro, Fakultas Teknologi Industri, Institut Teknologi Sepuluh Nopember (ITS) \\ Jl. Arief Rahman Hakim, Surabaya 60111 Indonesia \\ e-mail: rahmadhi.prihandono12@mhs.ee.its.ac.id, rameli@ee.its.ac.id
}

\begin{abstract}
Abstrak-Frekuensi sebesar $50 \mathrm{~Hz}$ harus dijaga agar memberikan kualitas energi listrik yang baik. Pengaruh dari switching pada sisi beban akan membuat frekuensi energi listrik menjadi fluktuatif. Nilai frekuensi yang fluktuatif akan membuat fungsi derivatif pada kontroler Proportional Integral Derivative (PID) menjadi sangat besar, sehingga akan mempengaruhi sinyal kontrol. Nilai tersebut memaksa aktuator bekerja sangat cepat dan akan mengurangi masa pemakaian aktuator. Penambahan filter pada kontroler PID untuk sistem pengaturan pembangkitan energi listrik mampu meredam noise yang timbul akibat fluktuasi beban. Penambahan Low Pass Filter (LPF) pada sisi derivatif memberikan redaman noise begitu pula menggunakan fungsi Averaged Derivative (AD). Dengan beban acak yang dimodelkan dengan Pseudo Random Binary Sequences (PRBS), nilai kesalahan dengan perhitungan Integral Absolute Error (IAE) terkecil dimiliki oleh PID dengan averaged derivative sebesar 110,246 Hz dan PID dengan low pass filter sebesar 110,486 Hz.
\end{abstract}

Kata Kunci-Load Frequency Control, Low Pass Filter, High Frequency Noise, Averaged Derivative.

\section{Pendahuluan}

$\mathrm{E}^{\mathrm{n}}$ nergi listrik di Indonesia memiliki frekuensi standar sebesar $50 \mathrm{~Hz}$. Energi listrik dihasilkan dari berbagai macam pembangkit yang terintegrasi untuk melayani beban dalam cakupan area tertentu. Perubahan beban yang tidak mampu direspon oleh pembangkit akan membuat area tersebut mengalami blackout dan pada sisi pembangkit listrik mengalami trip.

Beban membutuhkan suplai daya aktif dan reaktif. Pengaruh daya aktif akan berdampak pada frekuensi sedangkan daya reaktif berpengaruh pada tegangan bus. Penting untuk menjaga frekuensi agar tetap stabil. Apabila tidak tercapai, beban-beban industri berupa motor sinkron tidak dapat berjalan dengan semestinya.

Metode kontrol yang umum diterapkan pada pembangkitan energi listrik adalah Proportional dan Integral (PI) daripada menggunakan Proportional, Integral dan Derivative (PID). Switching pada sisi beban memicu noise yang akan berdampak pada nilai frekuensi energi listrik [1]. Pengaruh noise pada fungsi derivatif kontroler PID membuat keluaran kontroler menjadi fluktuatif.
Di sisi lain, kontroler PID akan memberikan solusi yang lebih baik daripada kontroler PI apabila permasalahan dari noise dapat diselesaikan. Terdapat metode yang sudah diusulkan untuk menyelesaikan masalah tersebut, yaitu dengan menggunakan Low Pass Filter (LPF) pada fungsi derivatif pada kontroler PID. Metode tersebut berpotensi menimbulkan adanya ketidakstabilan dari penggunaan LPF dikarenakan naiknya nilai gain kontroler [1].

Selain dengan menggunakan LPF, dapat menggunakan metode kontrol PID dengan Averaged Derivative (AD). Dengan menggunakan AD pada umpan balik akan didapat frekuensi dengan noise teredam.

Dalam penelitian ini bagian II akan membahas mengenai konsep sistem pengaturan energi listrik dan metode yang digunakan. Perancangan kontroler dan filter pada sistem pengaturan energi listrik akan dibahas pada bagian III. Pengujian dari metode, dengan perubahan beban dan variasi parameter filter akan dibahas pada bagian IV. Konklusi dari penelitian ini akan dibahas pada bagian $\mathrm{V}$.

\section{Sistem PENGATURAN ENERGI LISTRIK}

\section{A. Load Frequency Control}

Uap yang masuk dalam turbin diatur flow-nya oleh control valve (CV), uap tersebut akan menghasilkan torsi mekanik $\left(\mathrm{T}_{\mathrm{m}}\right)$. Akibat efek pembebanan akan muncul torsi elektrik $\left(\mathrm{T}_{\mathrm{e}}\right)$ yang melawan arah dari $\mathrm{T}_{\mathrm{m}}$. Governor akan membaca kecepatan turbin yang berubah dan kemudian akan menyesuaikan putaran turbin pada nilai seharusnya dengan mengatur bukaan dari CV. Mengendalikan kecepatan turbin dalam daerah terisolasi maka akan mengatur nilai frekuensi energi listrik. Dalam konsep Load Frequency Control (LFC) sejumlah pembangkit menyuplai beban bersama-sama. Pemodelan yang digunakan pada penelitian ini adalah LFC dengan dua pembangkit, maka dimodelkan seperti pada Gambar 1 . 


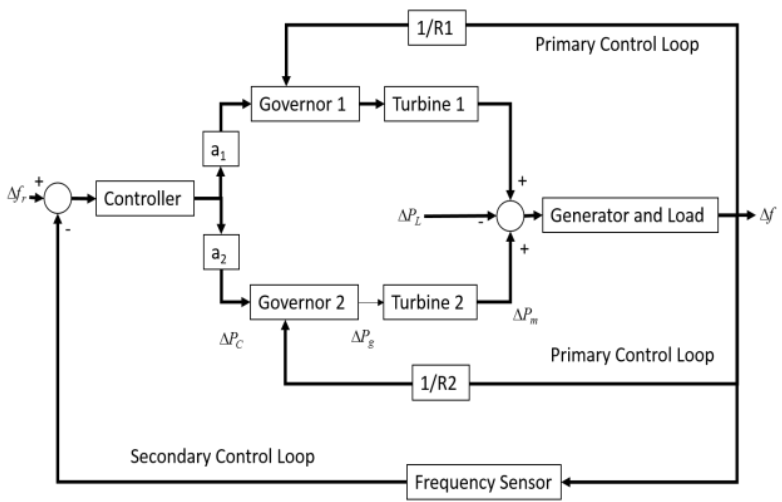

Gambar1. Pembangkit menyuplai daerah terisolasi

Dalam sistem pengaturan energi listrik, untuk beban yang terisolasi pengaturan frekuensi diatur melalui primary control loop dan secondary control loop. Pada primary control loop terletak pada pembangkit, sedangkan secondary control loop terletak diluar pembangkit. Primary control loop bertujuan untuk menjaga frekuensi tidak menurun ketika perubahan beban terjadi, sedangkan secondary control loop berperan dalam mengurangi eror frekuensi seminimum mungkin dan aliran daya antar area.

\section{B. Pemodelan Pembangkit}

Dalam LFC, sejumlah pembangkit menyuplai beban baik yang terhubung dengan area lain, ataupun tidak. Untuk penelitian ini digunakan dua pembangkit yang menyuplai beban namun dalam satu area. Pembangkit yang dimodelkan merupakan pembangkit termal dengan governor $(\mathrm{V}(\mathrm{s}))$ yang menggunakan Digital Electro Hydraulic Control (DEHC). Turbin (T(s)) yang digunakan merupakan turbin tandem compound, generator $(\mathrm{G}(\mathrm{s}))$ memiliki karakteristik putaran sebesar 3600 RPM dan memiliki jumlah kutub sepasang. Spesifikasi tersebut mengacu pada peralatan pembangkitan yang terdapat pada PT PJB UP Paiton Unit 1. Komponen yang terdapat pada pembangkit ditunjukkan olehGambar.

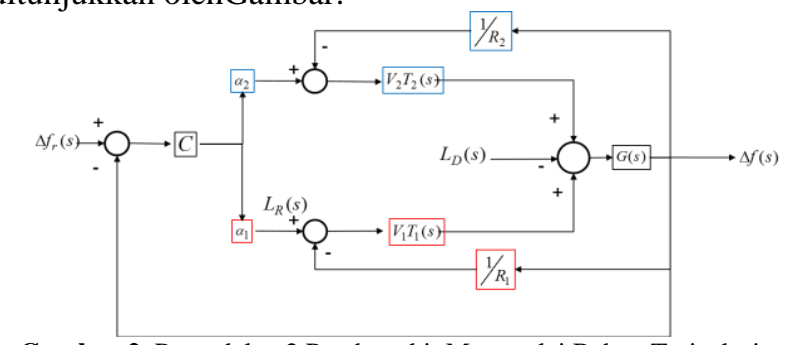

Gambar 2. Pemodelan 2 Pembangkit Menyuplai Beban Terisolasi

Untuk memodelkan primary control loop maka digunakan parameter yang terdapat pada [2]. Diagram blok keseluruhan sistem pembangkit ditunjukkan oleh Gambar . Dalam Diagram blok tersebut beban disuplai oleh dua pembangkit yang beroperasi parallel. Simulasi yang dibangun berdasarkan pada Tabel dengan maksimum kemampuan Pembangkit 1 adalah $250 \mathrm{MW}$ dan Pembangkit 2 adalah 100 MW.

\begin{tabular}{ll}
\multicolumn{2}{c}{ TABEL 1. PARAMETER SIMULASI } \\
\hline Parameter & Nilai \\
\hline Step time size & $0,01 \mathrm{~s}$ \\
Max $P 1$ & $450 \mathrm{MW}$ \\
Max $P 2$ & $300 \mathrm{MW}$ \\
Power base & $750 \mathrm{MVA}$ \\
Frequency base & $50 \mathrm{~Hz}$ \\
Current Load Condition & $400 \mathrm{MW}$
\end{tabular}

\begin{tabular}{ll} 
Current PI Output & $200 \mathrm{MW}$ \\
Current P2 Output & $200 \mathrm{MW}$ \\
Current System Frequency & $50 \mathrm{~Hz}$ \\
\hline
\end{tabular}

Pada primary loop control memiliki parameter karakteristik droop (R). Nilai tersebut merupakan perbandingan antara perubahan frekuensi saat steady state terhadap perubahan keluaran daya pembangkit.

\begin{tabular}{ccc}
\multicolumn{3}{c}{ TABEL 2. KARAKTERISTIK DROOP PEMBANGKIT } \\
\hline \hline Karakteristik Droop & R (\%) & R (puHz/puMW) \\
\hline $\mathrm{R}_{1}$ & $5 \%$ & 0,0833 \\
$\mathrm{R}_{2}$ & $4 \%$ & 0,1 \\
\hline
\end{tabular}

Dalam pemodelan digunakan pembangkit yang memiliki karakteristik droop berbeda yaitu 5\% dan 4\%, seperti pada Tabel . Dengan mengubah dalam bentuk perunit sistem yaitu dengan power base sebesar $750 \mathrm{MW}$ dan frekuensi sebesar $50 \mathrm{~Hz}$. Dari hasil desain nilai droop tersebut maka Pembangkit 1 akan menghasilkan daya yang lebih besar daripada Pembangkit 2. Efek droop tersebut nampak pada Gambar .

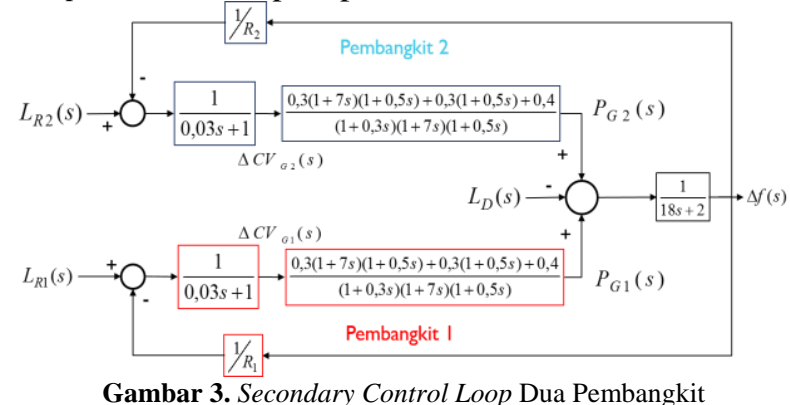

Sinyal kontrol yang terdapat pada kontroler (C), pada Gambar, terbagi oleh pada setiap pembangkit. Besarnya pembagian tersebut berdasarkan pada faktor partisipasinya $(\alpha)$. Dalam suatu pembangkitan yang menyuplai suatu area total dari faktor partisipasi dari seluruh pembangkit $\mathrm{k}$ pada area $\mathrm{i}$ adalah 1 , sebagaimana pada Persamaan 1.

$\sum_{k=1}^{n} \alpha_{k i}=1,0 \leq \alpha_{k i} \leq 1$

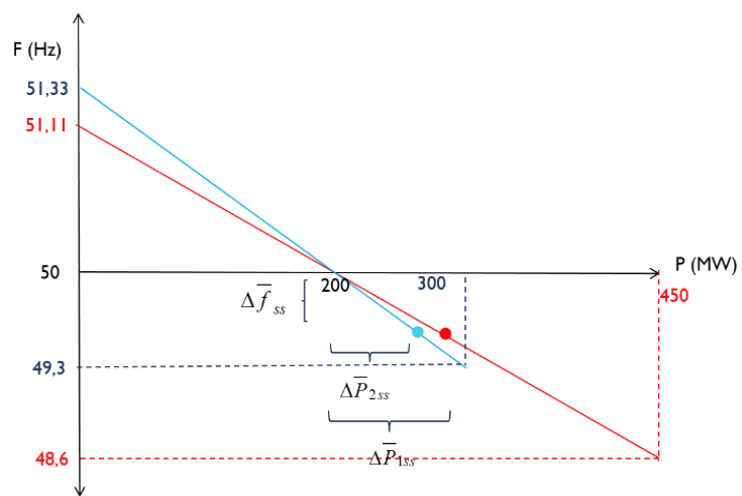

Gambar 4. Karakteristik Droop Dua Pembangkit

\section{Kontroler PID}

Respon yang diberikan plant kerap kali tidak sesuai dengan keinginan. Kontroler PID memiliki tiga komponen utama, yaitu proporsional, integral dan derivatif yang memiliki fungsi dan peranan masing masing dalam menentukan sinyal kontrol ke aktuator. Struktur kontroler PID ditunjukkan oleh Persamaan 2. 


$$
u(t)=K\left(e(t)+\frac{1}{T i} \int_{0}^{t} e(t) d t+T d \frac{d e(t)}{d t}\right)
$$

Dimana $\mathrm{u}(\mathrm{t})$ adalah sinyal kontol dan e(t) adalah sinyal eror yang merupakan masukan kontroler. Secara ringkas pengaruh parameter kontroler terhadap respon dapat dilihat pada Tabel .

TABEL 3. PENGARUH PARAMATER KONTROLER PID TERDAHADAP RESPON SISTEM

\begin{tabular}{|c|c|c|c|c|}
\hline & Rise Time & Overshoot & Settling Time & $\begin{array}{c}\text { Eror Steady } \\
\text { State }\end{array}$ \\
\hline $\mathrm{Kp}$ & Berkurang & Bertambah & $\begin{array}{c}\text { Tidak banyak } \\
\text { perubahan }\end{array}$ & Berkurang \\
\hline $\mathrm{Ki}$ & Berkurang & Bertambah & Bertambah & Tidak terdapat \\
\hline $\mathrm{Kd}$ & $\begin{array}{c}\text { Tak banyak } \\
\text { perubahan }\end{array}$ & Berkurang & Berkurang & Tidak berubah \\
\hline
\end{tabular}

Switching yang cepat pada beban menyebabkan perubahan nilai frekuensi. Nilai kesalahan yang diproses kontroler PID merupakan kesalahan nilai frekuensi, seperti pada Persamaan 3. Pengaruh keluaran kontroler tersebut terhadap noise diketahui dengan melakukan transformasi Fourier, dengan mengasumsikan kondisi awal adalah nol, maka diperoleh Persamaan 4. Besarnya magnitudo dari fungsi derivatif bergantung pada besarnya frekuensi, seperti pada Persamaan 5.

$$
\begin{aligned}
& \left.u_{D}(t)=K . T d \frac{d e(t)}{d t}\right) \\
& U_{D}(j \omega)=K \cdot T d j \omega \\
& \left|U_{D}(j \omega)\right|=|K . T d \omega|
\end{aligned}
$$

\section{PID Low Pass Filter}

Untuk menghilangkan sinyal yang tidak diinginkan dalam pada kontroler PID dapat digunakan filter. Sinyal noise yang ingin diredam adalah sinyal dengan frekuensi tinggi. Maka dengan low pass filter orde pertama pada sisi derfivatif dari kontroler PID seperti yang ditunjukkan pada Persamaaan 6, memiliki karakteristik tersebut.

$$
U(s)=K p\left(1+K d s \frac{1}{\tau s+1}+\frac{K i}{s}\right) E(s)
$$

Dengan $\tau$ merupakan frekuensi cut off. Frekuensi cut off merupakan titik frekuensi dimana besarnya redaman adalah $1 / \sqrt{2}$. Pemilihan $\boldsymbol{\tau}$ akan berpengaruh pada besarnya penguatan yang diberikan untuk range frekuensi pada filter, seperti pada Persamaan 7.

$$
\left|U_{D}(j \omega)\right|=\frac{|K p K d \omega|}{\left|\sqrt{\tau^{2} \omega^{2}+1}\right|}
$$

\section{E. PID dengan Averaged Derivative}

Fungsi averaged derivative merupakan suatu fungsi matematis yang digunakan untuk menentukan nilai turunan dan kemudian dirata - rata kan. Terdapat dua komponen fungsi yaitu, rata rata dan turunan yang dituliskan dalam Persamaan 8.

$\left[f(t)^{\prime}\right]_{\text {avg }}=\frac{1}{T} \int_{t-T}^{t} \frac{d(f(t)}{d t} d t$

Dari Persamaan 8, parameter T merupakan time delay pada fungsi averaged derivative. Besarnya $\mathrm{T}$ mempengaruhi fungsi derivatif pada kontroler PID, seperti yang ditunjukkan pada Persamaan 9. Semakin kecil nilai $\mathrm{T}$ maka fungsi averaged derivative menyerupai fungsi derivatif.
$U(s)=K p\left(1+\frac{K d}{T}\left(1-e^{-T s}\right)+\frac{K i}{s}\right) E(s)$

\section{Perancangan LoAd FreQuency Control untuk DUA PEMBANGKIT}

\section{A. Faktor Partisipasi}

Participating factor berperan dalam mengatur partisipasi pembangkit dalam menyuplai beban pada secondary control loop [3]. Dalam penelitian ini dibuat partisipasi pembangkit 1 lebih besar dikarenakan kapasitas yang lebih besar yaitu 400MW atau nilai faktor partisipasi Pembangkit $1\left(\alpha_{1}\right)$ adalah 0,6 dan Pembangkit $2\left(\alpha_{2}\right)$ adalah 0,4 .

\section{B. Reduksi Model dengan Pendekatan Routh [3]}

Model primary control loop memiliki model dengan orde tinggi, sehingga akan menyulitkan apabila dilakukan perancangan kontroler tanpa melakukan penyederhanaan model. Pendekatan Routh dapat dilakukan untuk mereduksi model orde tinggi seperti pada Persamaan 10.

$\frac{\Delta f(s)}{L_{R}(s)}=\frac{V(s) T(s) G(s)}{T(s) V(s) G(s)\left(\frac{1}{R_{1}}+\frac{1}{R_{2}}\right)+1}$

Langkah-langkah untuk melakukan reduksi fungsi alih (H(s)) dengan pendekatan Routh:

1. Melakukan reciprocal transformation dengan menggunakan Persamaan 11. Dari hasil tersebut akan didapat nilai konstanta numerator dan denumerator yang berbalik seperti pada Persamaan 12 .

$$
\begin{aligned}
& \hat{H}(s)=\frac{1}{s} H\left(\frac{1}{s}\right) \\
& \hat{H}(s)=\frac{b_{1} s^{n-1}+\ldots+b_{n}}{a_{0} s^{n}+a_{1} s^{n-1}+\ldots+a_{n}}
\end{aligned}
$$

\begin{tabular}{|c|c|c|c|c|c|}
\hline & $\begin{array}{l}a_{0}^{0}=a_{0} \\
a_{0}^{1}=a_{1}\end{array}$ & $\begin{array}{l}a_{2}^{0}=a_{2} \\
a_{2}^{1}=a_{3}\end{array}$ & $\begin{array}{l}a_{4}^{0}=a_{4} \\
a_{4}^{1}=a_{5}\end{array}$ & $a_{6}^{0}=a_{6}$ & \\
\hline$\alpha_{1}=a_{0}^{0} / a_{0}^{1}$ & $a_{0}^{2}=a_{2}^{0}-\alpha_{1} a_{2}^{1}$ & $a_{2}^{2}=a_{4}^{0}-\alpha_{1} a_{4}^{1}$ & $a_{4}^{2}=a_{4}^{0}-\alpha_{1} a_{4}^{1}$ & $\ldots \ldots \ldots$ & \\
\hline$\alpha_{2}=a_{0}^{1} / a_{0}^{2}$ & $a_{0}^{3}=a_{2}^{1}-\alpha_{2} a_{2}^{2}$ & $a_{2}^{3}=a_{4}^{1}-\alpha_{2} a_{4}^{2}$ & 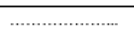 & & \\
\hline$\alpha_{3}=a_{0}^{2} / a_{0}^{3}$ & $a_{0}^{4}=a_{2}^{2}-\alpha_{3} a_{2}^{3}$ & ………… & 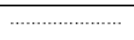 & & \\
\hline & & & & & \\
\hline
\end{tabular}

2. Konstanta numerator dan denumerator pada hasil

\begin{tabular}{|c|c|c|c|c|c|}
\hline & $\begin{array}{l}b_{0}^{1}=b_{1} \\
b_{0}^{2}=b_{2}\end{array}$ & $\begin{array}{l}b_{2}^{1}=b_{3} \\
b_{2}^{2}=b_{4}\end{array}$ & $\begin{array}{l}b_{4}^{1}=b_{5} \\
b_{4}^{2}=b_{6}\end{array}$ & $\begin{array}{l}b_{8}^{1}=b_{7} \\
-. .\end{array}$ & $\cdots \cdots . .$. \\
\hline$\beta_{1}=b_{0}^{1} / a_{0}^{1}$ & $b_{0}^{3}=b_{2}^{t}-\beta_{1} a_{2}^{t}$ & $b_{2}^{3}=b_{4}^{1}-\beta_{1} a_{4}^{t}$ & $a_{4}^{2}=a_{4}^{0}-\alpha_{1} a_{4}^{2}$ & $\ldots \ldots \ldots$ & \\
\hline$\beta_{2}=b_{0}^{2} / a_{0}^{2}$ & $b_{0}^{4}=b_{2}^{2}-\beta_{2} a_{2}^{2}$ & $b_{2}^{4}=b_{4}^{1}-\beta_{2} a_{4}^{2}$ & 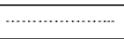 & & \\
\hline$\beta_{3}=b_{0}^{3} / a_{0}^{3}$ & $b_{0}^{5}=b_{2}^{2}-\beta_{1} a_{2}^{3}$ & ․․………........ & 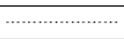 & & \\
\hline
\end{tabular}
fungsi alih yang telah dilakukan reciprocal transformation kemudian dimasukkan pada Tabel Alpha (Tabel )Tabel dan Beta (Tabel )untuk mencari nilai Apha dan Beta.

TABel 4. TABel ALPHA

TABEL 5. TABEL BeTA

3. Setelah mendapatkan nilai Alpha dan Beta, dicari fungsi polinomial s A(s) dan B(s) sebanyak $\mathrm{k}$. Nilai $\mathrm{k}$ bergantung pada jumlah alpha dan beta. Fungsi A(s) ditunjukkan oleh Persamaan 13 dan B(s) Ditunjukkan oleh Persamaan 14.

$$
\begin{aligned}
& A_{k}(s)=\alpha_{k} s A_{k-1}(s)+A_{k-2}(s) \\
& B_{k}(s)=\alpha_{k} s B_{k-1}(s)+B_{k-2}(s)+\beta_{k}
\end{aligned}
$$


4. Nilai $A(s)$ dan $B(s)$ selanjutanya dibentuk fungsi alih dengan $\mathrm{B}(\mathrm{s})$ adalah numerator dan $\mathrm{A}(\mathrm{s})$ adalah denumerator seperti yang ditunjukkan oleh Persamaan 15.

$$
\hat{R}_{k}(s)=\frac{B_{k}}{A_{k}}
$$

5. Dilakukan reciprocal transformation (Persamaan 16) untuk setiap nilai $R_{k}$ pada Persamaan 15 , sehingga didapat fungsi alih hasil reduksi sebanyak $\mathrm{k}$ seperti pada Persamaan 17.

$$
\begin{aligned}
& H_{k}(s)=\frac{1}{s} \hat{R}_{k}\left(\frac{1}{s}\right) \\
& H_{k}(s)=\frac{d_{1} s^{k-1}+\ldots+d_{k}}{c_{0} s^{k}+c_{1} s^{k-1}+\ldots+c_{k}}
\end{aligned}
$$

Hasil pendekatan diperoleh sebanyak 10 buah, dengan orde terendah yaitu orde kesatu dan tertinggi orde kesepuluh. Model hasil reduksi dipilih orde yang memiliki derajat rendah dan memiliki nilai kesalahan yang kecil. Hasil perbandingan tersebut ditunjukkan oleh Gambar 5.

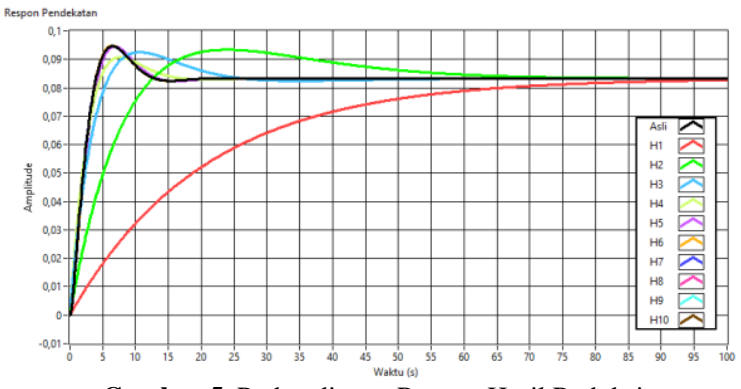

Gambar 5. Perbandingan Respon Hasil Reduksi

Dengan membandingkan kesepuluh model seperti pada Tabel , maka dipilih model orde kedua. Hasil reduksi pendekatan orde kedua memiliki nilai Integral Absolute Error (IAE) sebesar 7,73 dan nilai Root Mean Square Error (RMSE) sebesar 0,010339.

TABEl 6. PERBANDINGAN NILAI KESAlahan HASIL REDUKSI

\begin{tabular}{ccc}
\hline \hline Pendekatan & IAE & RMSE \\
\hline $\mathrm{H}_{1}$ & 21,3545 & 0,0244962 \\
$\mathrm{H}_{2}$ & 7,73974 & 0,010339 \\
$\mathrm{H}_{3}$ & 2,20237 & 0,00331019 \\
$\mathrm{H}_{4}$ & 0,823591 & 0,00159039 \\
$\mathrm{H}_{5}$ & 0,314004 & 0,000674194 \\
$\mathrm{H}_{6}$ & 0,0855847 & 0,000230823 \\
$\mathrm{H}_{7}$ & 0,0254744 & $6,19310^{-5}$ \\
$\mathrm{H}_{8}$ & 0,00904523 & $7,34110^{-6}$ \\
$\mathrm{H}_{9}$ & 0,00837382 & $6,29710^{-6}$ \\
$\mathrm{H}_{10}$ & 0,00818326 & $6,18610^{-6}$ \\
\hline
\end{tabular}

Fungsi alih dari hasil pendekatan orde kedua yaitu $\mathrm{H}_{2}$ (s) memiliki nilai seperti pada Persamaan 18.

$$
H(s)=\frac{0,0131 s+0,000683}{s^{2}+0,168 s+0,0082}
$$

\section{Spesifikasi Respon}

Standar untuk pembangkitan energi listrik diatur oleh Kementrian Energi dan Sumber Daya Alam, dinginkan pada standar tersebut error steady state mendekati $0 \%$ [5]. Untuk mendapatkan kesalahan mendakti nol, maka penguatan sistem dengan kontroler adalah $1 \quad(\mathrm{~K}=1)$. Perubahan beban akan mengakibatkan perubahan frekuensi, agar frekuensi tidak mengalami osilasi akibat perubahan beban maka diinginkan parameter zeta $(\zeta)$ adalah satu.

\section{Desain Kontroler PID}

Plant hasil reduksi merupakan sistem dengan orde kedua, untuk memenuhi spesifikasi nilai error steady state mendekati nol maka digunakan kontroler PID. Perancangan kontroler menggunakan bantuan pemetaan akar-akar agar memudahkan dalam mengethaui letak pole dan zero dari sistem yang mempengaruhi karakteristik respon.

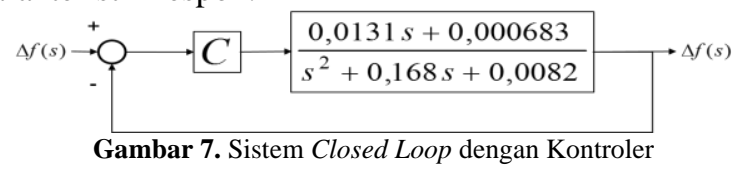

Untuk mengetahui parameter kontroler yang sesuai, perlu ditinjau terlebih dahulu bagaiamana karakteristik respon dari plant. Hal tersebut dapat dicapai dengan menggambarkan letak akar-akar persamaan karakteristik. Seperti pada Gambar, letak poles berada pada sumbu imajiner dan riil. Letak poles tersebut membuat nilai $\zeta$ dari sistem tidak sama dengan 1 , sehingga terdapat overshoot dari sistem.

$$
\frac{\Delta f(s)}{\Delta f_{r}(s)}=\frac{C(s) \frac{0,0131 s+0,000683}{s^{2}+0,168 s+0,0082}}{1+C(s) \frac{0,0131 s+0,000683}{s^{2}+0,168 s+0,0082}}
$$

Kontroler PID memiliki dua buah zero dan satu pole dengan meletakkan zero pada pole plant akan menghilangkan pole tersebut sehingga locus dari sistem dengan kontroler hanya terletak pada sumbu riil. Dengan demikian, dibentuk closed loop dengan symbol kontroler C seperti pada Gambar . Fungsi alih yang terbentuk adalah seperti pada Persamaan 19.

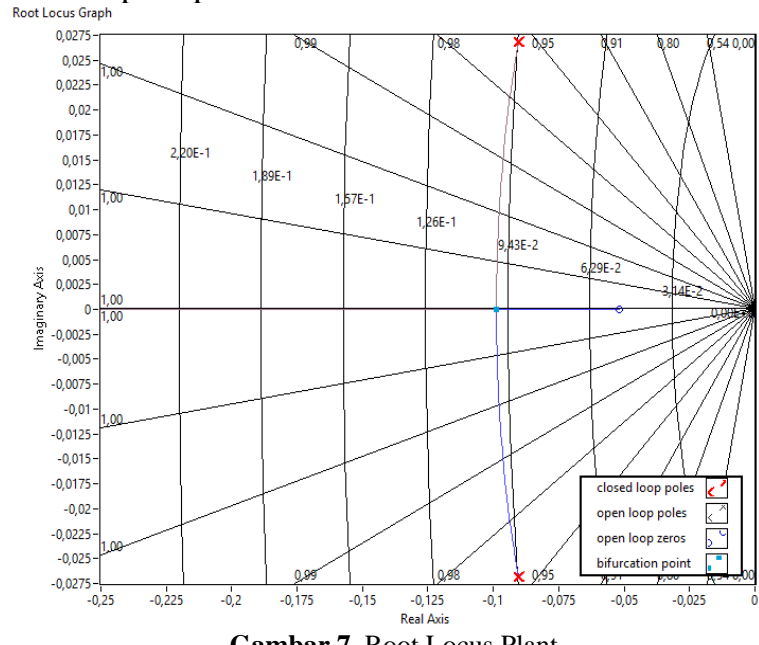

Dengan memilih parameter $\tau_{i}=20,44$ sekon dan $\tau_{d}=$ 5,95 sekon membuat poles plant menjadi terbatalkan pada Persamaan 18. Hasil penyederhanaan dari fungsi alih dengan parameter kontroler tersebut ditunjukkan oleh Persamaan 20. Akibat pembatan poles dan zeros, maka root locus sistem closed loop menjadi seperti pada Gambar .

$$
\frac{\Delta f}{\Delta f_{r}}=\frac{1}{1+\left(19,18+\frac{246}{K_{P}}\right) s}
$$

Diperoleh pada Persamaan 20, nilai penguatan K adalah satu. Maka dengna nilai tersebut besarnya 
kesalahan dapat mendekatai nol. Nilai parameter time constant $(\tau)$ bergantung pada besarnya nilai Kp.

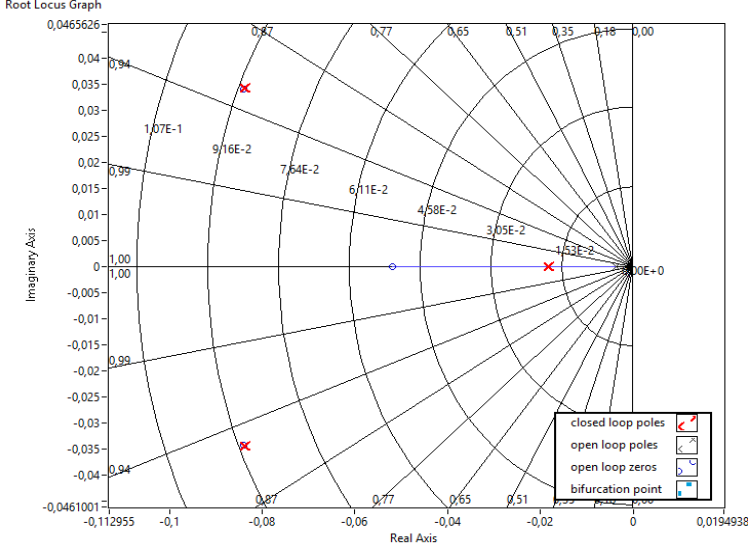

Gambar 8. Closed Loop System Root Locus

\section{E. Desain PID Low Pass Filter}

Fungsi low pass filter memiliki parameter time constant $(\tau)$ seperti pada Persamaan 21. Besarnya parameter tersebut mempengaruhi nilai frequency cut off seperti pada Persamaan 22. Noise yang ditimbulkan dari simulasi memiliki frekuensi sebesar $50 \mathrm{~Hz}$. Diinginkan redaman terletak pada $2 \mathrm{~Hz}$, maka diperoleh nilai $\tau$ sebesar 0,1 sekon. Hasil redaman dari parameter tersebut adalah $1,56 \mathrm{~Hz}$.

$$
\begin{aligned}
& H(s)=\frac{1}{1+\tau s} \\
& f_{c}=\frac{1}{2 \pi \tau}
\end{aligned}
$$

\section{F. Penentuan Parameter Time Delay pada PID Averaged Derivative}

Parameter time delay (T) dipilih nilai sekecil mungkin, namun tidak boleh melebihi nilai terkecil dari time constant system [1]. Pemilihan melebihi $\mathrm{T}$ yang besar dapat menyebabkan delay pada fungsi differential. Berdasarkan Tabel, nilai time constant terkecil sistem adalah 0,029 sekon. Berdasarkan nilai tersebut dipilih parameter $\mathrm{T}$ sebesar 0,01 sekon.

\begin{tabular}{cc}
\multicolumn{2}{c}{ TABEL 7. POLES PLANT } \\
\hline \hline Poles & Nilai \\
\hline $\mathrm{P}_{1}$ & $-2,21$ \\
$\mathrm{P}_{2}$ & $-3,33$ \\
$\mathrm{P}_{3}$ & -2 \\
$\mathrm{P}_{4}$ & $-2,75$ \\
$\mathrm{P}_{5}$ & $-33,37$ \\
$\mathrm{P}_{6}$ & $-33,33$ \\
$\mathrm{P}_{7}$ & $-0,14$ \\
$\mathrm{P}_{8}$ & $-0,11$ \\
$\mathrm{P}_{9}$ & $-0,29-0,35 \mathrm{i}$ \\
$\mathrm{P}_{10}$ & $-0,29+0,35 \mathrm{i}$ \\
\hline \hline
\end{tabular}

\section{ANALISA DAN PENGUJIAN PADA SECONDARY CONTROL} LOOP

Beban berupa unit step akan diberikan sekaligus dengan beban acak yang diakibatkan oleh switching pada sisi beban. Pemberian beban tersebut bertujuan menguji kontroler PID dan filter yang telah dirancang. Simulasi dilakukan selama 150 detik dengan kenaikan beban sebesar $20 \mathrm{MW}$ pada detik ke 10. Selama simulasi berlangsung beban acak telah ditambahkan, yaitu sebesar $+5 \mathrm{MW}$ hingga $-5 \mathrm{MW}$.
TABEL 8. VARIASI PARAMETER T DAN $\tau$ TERHADAP KeSALAHAN FREKUENSI

\begin{tabular}{ccc}
\hline \hline Variasi T dan $\boldsymbol{\tau}$ & IAE PID AD $(\mathbf{H z})$ & IAE PID LPF $(\mathbf{H z})$ \\
\hline 5 sekon & 111,129 & 111,195 \\
1 sekon & 111,222 & 110,708 \\
0,1 sekon & 109,481 & 109,612 \\
0,03 sekon & 109,673 & 109,73 \\
0,01 sekon & 108,877 & 108,904 \\
\hline \hline
\end{tabular}

Perbandingan Tabel menunjukkan nilai kesalahan dari perubahan frekuensi, yaitu $50 \mathrm{~Hz}$. Dalam tabel tersebut menunjukkan bahwa kedua variasi time delay (LFC dengan metode kontrol PID Averaged Derivative (AD)) dan time constant (LFC dengan metode kontrol PID Low Pass Filter (LPF)) semakin baik apabila digunakan nilai yang semakin kecil.

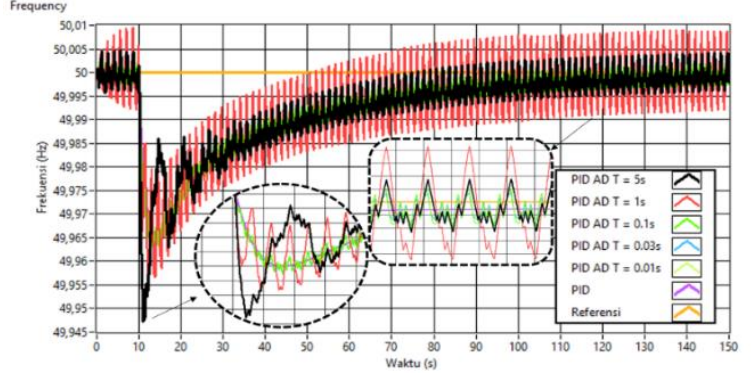

Gambar 9. Pengaruh Variasi Parameter Time Delay terhadap Perubahan Frekuensi untuk Beban Acak

Untuk pengaruh variasi parameter time delay dengan nilai $5 \mathrm{~s}$ memiliki differential delay yang besar yaitu dengan nilai sebesar 111,129 Hz (kurva hitam). Parameter $\mathrm{T}$ sebesar 1 sekon juga terdapat differential delay yang tidak sebesar $\mathrm{T}$ untuk nilai 5 sekon, yaitu 111,222 Hz. Hal tersebut dikarenakan pemilihan T yang besar, sehingga fungsi averaged derivative pada Persamaan 23 tidak menyerupai fungsi turunan pada kontroler PID.

$\left[f(t)^{\prime}\right]_{\text {avg }}=\frac{1}{T}[F(t)-F(t-T)]$

Time delay hasil desain sebesar 0,01 sekon memiliki kesalahan terkecil dari perbandingan yang dilakukan, yaitu $108,877 \mathrm{~Hz}$. Dengan demikian pemilihan time delay mungkin membuat kesalahan frekuensi semakin kecil.

Pemilihan parameter time delay dari hasil pengujian berdampak pada sinyal kontrol yang ditunjukkan oleh Gambar . Pada saat pemberian beban acak sebesar 20 MW, sinyal kontrol dengan parameter time delay terbesar memiliki respon yang lebih landai (kurva hitam dan merah) apabila dibandingkan dengan sinyal kontrol untuk parameter time delay yang lebih kecil $(0,1$ sekon, 0,03 sekon, dan 0,01 sekon).

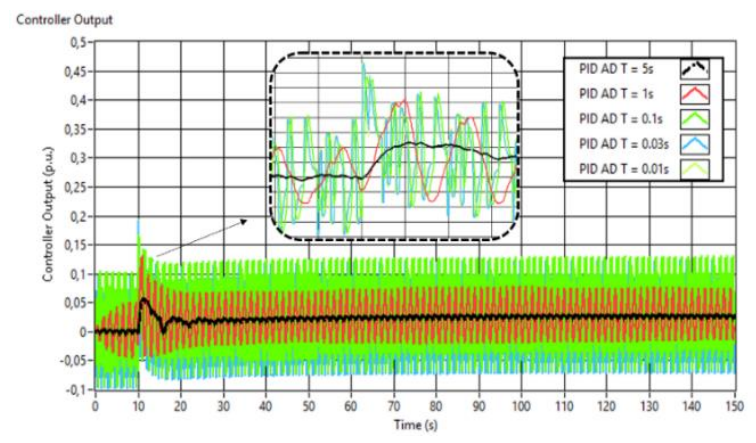

Gambar 10. Pengaruh Variasi Parameter Time Delay terhadap Sinyal Kontrol untuk Beban Acak 
Pemilihan time delay yang sangat kecil membuat sinyal kontrol menjadi fluktuatif. Pembangkit harus mampu mengikuti perubahan sinyal kontrol tersebut. Pada kenyataanya, respon pembangkit membutuhkan waktu yang lama dibandingkan dengan sinyal kontrol yang diterima pembangkit.

Untuk LFC dengan metode kontrol PID LPF memiliki perubahan respon untuk nilai time constant filter sebesar 5 sekon (kurva hitam). Hal tersebut disebabkan parameter time constant terlalu besar, sehingga merubah karakteristik dari sistem. Penggunaan fungsi low pass filter akan merubah pole zero controller dari sistem. Semakin kecil nilai pole maka akan semakin mempengaruhi respon waktu dari sistem seperti pada Persamaan 7. Perubahan respon waktu tersebut ditunjukkan oleh Gambar .

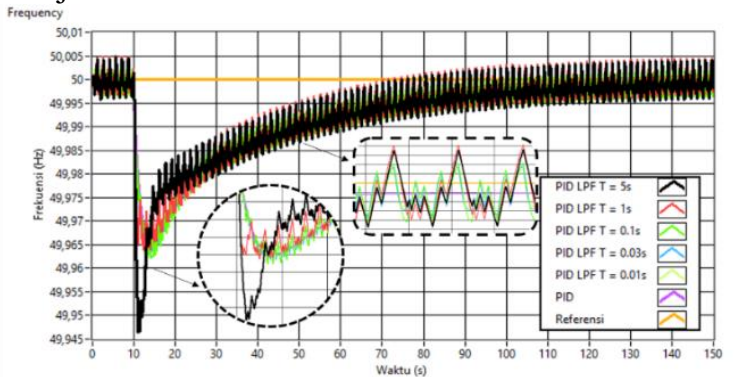

Gambar 11. Pengaruh Variasi Parameter Time Constant terhadap Perubahan Frekuensi untuk Beban Acak

Pengaruh parameter time constant terlihat pada Gambar untuk nilai 0,01 sekon memiliki fluktuasi yang paling kecil, yaitu 108,904 Hz (kurva berwarna kuning). Nilai kesalahan yang kecil tersebut memiliki sinyal kontrol yang fluktuatif seperti perbesaran dari Gambar untuk kurva yang berwarna sama.

Nilai sinyal kontrol yang fluktuatif tersebut diakibatkan frequency cut off yang besar (Persamaan 24). Nilai besar dari frequency cut off menyebabkan noise untuk frekeunsi dibawah nilai tersebut menjadi tidak teredam. Akibat nilai frequency cut off yang besar adalah noise yang tidak teredam pada sinyal kontrol. Sinyal kontrol yang memiliki berubah dengan cepat tidak mampu diikuti oleh pembangkit.

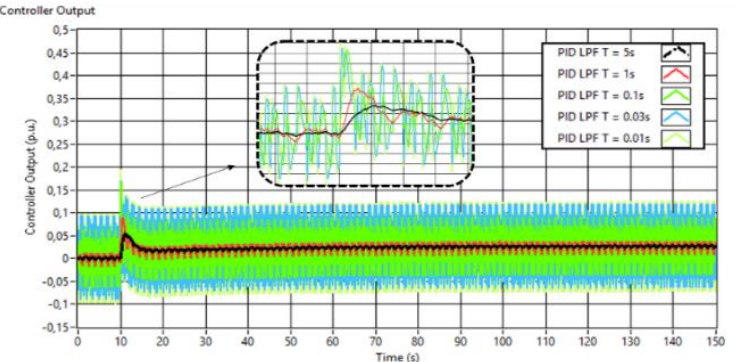

Gambar 12. Pengaruh Variasi Parameter Time Constant terhadap Sinyal Kontrol untuk Beban Acak

$$
f_{c}=\frac{1}{2 \pi \tau}
$$

\section{KesimpUlan}

Metode kontrol PID AD dan PID LPF memiliki respon yang serupa dengan metode kontrol PID untuk time constant dan time delay yang kecil semakin kecil maka akan menyerupai respon LFC yang menggunakan kontroler PID. Pemilihan time constant yang sama untuk LFC dengan PID low pass filter dan LFC dengan PID averaged derivative memiliki nilai kesalahan sebesar $110,486 \mathrm{~Hz}$ dan $110,246 \mathrm{~Hz}$.

Penggunaan kedua filter tersebut harus diperhatikan dari pembangkit yang terhubung menyuplai beban. Apabila pembangkit tidak mampu merespon perubahan beban yang cepat maka deviasi frekuensi yang terjadi akan semakin besar dan berdampak pada peralatanperalatan pada sisi beban.

\section{DAFTAR PUSTAKA}

[1] Y. H. Moon, H. S. Ryu, J. G. Lee, and S. Kim. "Power System Load Frequency Control Using Noise-Tolerable PID Feedback". In Proc. IEEE Int. Symposium on Industrial Electronics (ISIE), volume 3, pages 1714-1718, June 2001.

[2] Kundur, Prabha, "Power System Stability and Control", McGrawHill, 1994

[3] Hutton, Maurice F, "Routh Approximations for Reducing Order of Linear, Time-Invariant Systems", IEEE Transaction on Automatic Control, June 1975.

[4] ---, "PID Control and Derivative Measurement", <URL:http://controlguru.com/pid-control-and-derivative-onmeasurement/>, Desember 2016

[5] ---, " Aturan Jaringan Sistem Tenaga Listrik Jawa-Madura-Bali",, Menteri Energi dan Sumber Daya Mineral Republik Indonesia, 2007.

[6] Bevrani, Hassan. "Intelligent Automatic Generation Control", CRC Press, 1994 